\title{
Spatial Association and Distribution of Beet necrotic yellow vein virus and Beet soilborne mosaic virus in Sugar Beet Fields
}

\author{
F. Workneh, E. Villanueva, K. Steddom, and C. M. Rush, Texas Agricultural Experiment Station, Bushland \\ 79012
}

\begin{abstract}
Workneh, F., Villanueva, E., Steddom, K., and Rush, C. M. 2003. Spatial association and distribution of Beet necrotic yellow vein virus and Beet soilborne mosaic virus in sugar beet fields. Plant Dis. 87:707-711.

Beet necrotic yellow vein virus (BNYVV) causes rhizomania of sugar beet (Beta vulgaris), which is characterized by stunting, leaf necrosis, constriction of the taproot, and extensive lateral- and feeder-root proliferation. Beet soilborne mosaic virus (BSBMV) causes similar but typically less severe symptoms than those of BNYVV. Both viruses are widely distributed in sugar beet-growing regions of the United States. Both viruses are vectored by the soilborne plasmodiophorid Polymyxa betae Keskin and are very similar in morphology and biology, sharing many characteristics in common. In 1999, soil samples were collected from sugar beet fields in Colorado, Minnesota, North Dakota, and Texas to determine the spatial association and covariation of the viruses in sugar beet fields. In 2000, additional samples were collected from fields in Minnesota and North Dakota. Over the 2-year period, soil samples were collected from 11 fields in various quadrat sizes. The viruses were assayed by growing sugar beet (cv. Beta 1395) in the soil samples and their incidence was determined using the double-antibody sandwich enzyme-linked immunosorbent assay. Both viruses were detected in samples from all fields but were in greater frequencies singly than in association. Association of the two viruses (where both viruses were detected in the same sample or bait plant) varied among fields, ranging from 1 to $42 \%$. Geostatistical analysis revealed that both viruses, in large part, exhibited similar spatial patterns. In all but two fields, there was no spatial dependence among the sampling locations at sampled grid sizes. Their semivariances were constant at all separation distances in all directions indicating random spatial patterns. Overall, the spatial pattern of BNYVV appeared to be a little more structured than that of BSBMV. Even though both viruses are transmitted by the same vector and also exhibited similar distribution patterns, the incidence of one virus may not be estimated from that of the other due to lack of strong association and spatial dependence. However, similarity in spatial patterns of the two suggests that a similar sampling method can be employed for both viruses.
\end{abstract}

Beet necrotic yellow vein virus (BNYVV) causes rhizomania of sugar beet (Beta vulgaris). The disease is characterized by stunting, leaf necrosis, constriction of the taproot, and extensive lateral- and feeder-root proliferation (19). Rhizomania is a severe disease of sugar beet worldwide, affecting sugar beet yield and quality (19). Since first reported in the United States in 1984 (4), the disease has been widely observed in many sugar beet-growing regions of the United States, causing severe yield losses $(3,19)$.

Beet soilborne mosaic virus (BSBMV) was first reported from California and Texas in 1988 (13). A survey conducted in 1991 and 1992 showed that the virus was

Corresponding author: C. M. Rush

E-mail: cm-rush@tamu.edu

This research was supported by Minnesota-North Dakota Research and Education Board.

Accepted for publication 26 January 2003.

Publication no. D-2003-0410-01R

(C) 2003 The American Phytopathological Society widespread throughout the sugar beetgrowing regions of Texas and New Mexico (9). Since then, it frequently has been identified in Colorado, Minnesota, Nebraska, and Wyoming $(19,29)$. Unlike BNYVV, BSBMV had not been reported outside of the United States and its effect on sugar beet yield and quality is variable, depending on soil moisture and perhaps other variables (16). The two viruses differ primarily in serology and symptom expression on various host plants, including sugar beet $(10,28)$. Symptoms on sugar beet typically are less severe than those of BNYVV (10). BSBMV induces more systemic, mosaic-type symptoms than the leaf chlorosis typically associated with BNYVV. Root weights of sugar beet plants infected with BNYVV typically are significantly less than of those infected with BSBMV (10). However, the viruses are biologically more similar to each other than to other members of the genus Furovirus $(10,13,18)$. For this reason, they recently were moved into the genus Benyvirus, of which BNYVV is the type member (11). In addition, BNYVV and BSBMV both are vectored by zoospores of the soilborne plasmodiophorid Polymyxa betae Keskin (5), which infect primary root tissue of young sugar beet roots and transmit the viruses. A previous study in Texas showed that both viruses can be detected in the same field. In addition, when sugar beet was grown in bulked rhizosphere soil samples, both were able to infect the same sugar beet root (9). However, their relative frequencies and the magnitude of their distribution and association in individual rhizosphere soil in sugar beet fields have never been investigated.

In a greenhouse study, Mahmood and Rush (14) showed that, when sugar beet plants were inoculated with either of the viruses and challenged with the other after 2 or more days, in reciprocal inoculation, there was a high degree of interference. In another study, Piccinni and Rush (16) found that disease severity was lower and yields higher in field plots inoculated with combinations of BSBMV and BNYVV than in plots inoculated with BNYVV alone, corroborating the greenhouse finding. However, Wisler et al. (27) reported that, when sugar beet plants were grown in soil containing the two viruses, resulting in mixed infection, BSBMV levels were suppressed but BNYVV levels appeared to increase. Consequently, they concluded that there might be synergetic association between the two viruses. These findings suggest the existence of some form of interaction between the viruses, be it synergistic or interference. In order for the observed interactions to have any meaningful field implications, the two viruses have to be spatially associated under field conditions to infect the same plant. However, the spatial association of the viruses and their relative frequencies or distribution patterns under field conditions are unknown. Knowledge of the spatial association of the two viruses may give some insight into the potential for synergetic or antagonistic interaction under field conditions.

In sampling locations in which the incidence of the viruses exhibit spatial continuity, if the viruses (vectored by the same organism) are found to be highly associated, the frequency and distribution patterns of either virus could be estimated from that of the other based on the degree of covariance, saving time and resources. In addition, information on spatial association and distribution of the viruses may serve as a useful guideline in devising sampling strategies and designing field 
experiments. The primary objectives of this investigation were to (i) determine the frequency of association of BNYVV and BSBMV in sugar beet fields and (ii) determine whether the two viruses have similar spatial distributions.

\section{MATERIALS AND METHODS}

Sample collection. In the summer of sugar beet fields with a history of both BNYVV and BSBMV in Colorado (Fort Morgan area), Minnesota (Wilmar area), North Dakota (Fargo area), and Texas (Bushland) (one field from each state). The sizes of the fields ranged from 18 to 32 ha. At each site, samples were collected at two levels (Table 1). First, the entire field was divided into grids of 0.4 ha (large quadrats), and second, one of the large quadrats was arbitrarily selected and further divided into 3.4-by-7.6-m quadrats (small). In this study, unless otherwise stated, one plant near the center of each quadrat was selected and soil from around the root was collected.

In the summer of 2000 , soil samples were collected from five fields (L, LR, S1, $\mathrm{W} 1$, and $\mathrm{W} 4$,) in southern Minnesota and two fields (F2 and F3) in North Dakota, near Fargo (Table 2). One of the fields in Minnesota (L) comprised three plots of 1year, 2-year, and 3-year rotation ( $\mathrm{L} 1, \mathrm{~L} 2$, and L3, respectively) studies that included 1999, soil samples were collected from

corn, sugar beet, and soybean designed for a separate study. For this study, each plot (approximately 0.05 ha) was subdivided into 2.9 by $2.9 \mathrm{~m}$ quadrats for sample collection. Samples from LR and S1 were collected from the entire fields (20.5 and 34.8 ha, respectively) in grids of 0.4 and 1 ha, respectively. In four of the fields (F2, F3, W1, and W4), two areas showing symptomatic and nonsymptomatic plants were selected arbitrarily and subdivided into grid sizes of 2.9 by $2.9 \mathrm{~m}$ and sampled. As in field $\mathrm{L}$ above, this also was originally designed for a separate study. Samples were shipped overnight to the Texas Agricultural Experiment Station Laboratory in Bushland and were kept at $4^{\circ} \mathrm{C}$ until they were processed for bioassay and enzyme-linked immunosorbent assay (ELISA).

Virus assay. Each soil sample was mixed and a 40-g subsample was layered on top of $130 \mathrm{~g}$ of a pasteurized soil and sand mixture (10:1 wt/wt, respectively) which was laid on $2.5 \mathrm{~g}$ of peat moss (to prevent leakage of the soil and sand mixture) in 4-by-21-cm cone-shaped plastic containers (Stuewe and Sons, Corvallis, OR). Five sugar beet seed were planted in each cone and cones were placed in racks on greenhouse benches. The greenhouse temperature (measured by hygrothermographs) during the study ranged from 17.9 to $29.7^{\circ} \mathrm{C}$. The containers were watered as

Table 1. Frequencies of Beet necrotic yellow vein virus (BNYVV) and Beet soilborne mosaic virus (BSBMV) in samples collected from large and small quadrats in fields in Colorado, Minnesota, North Dakota, and Texas in 1999

\begin{tabular}{|c|c|c|c|c|c|}
\hline \multirow[b]{2}{*}{ Location, quadrat ${ }^{a}$} & \multirow[b]{2}{*}{ No. of samples } & \multicolumn{4}{|c|}{ Virus incidence (\%) } \\
\hline & & None & BNYVV & BSBMV & Both \\
\hline \multicolumn{6}{|l|}{ Colorado } \\
\hline Small & 70 & 20.0 & 8.6 & 51.4 & 20.0 \\
\hline Large & 59 & 50.9 & 15.3 & 28.8 & 5.1 \\
\hline \multicolumn{6}{|l|}{ Minnesota } \\
\hline Small & 118 & 43.9 & 21.2 & 17.8 & 17.8 \\
\hline Large & 79 & 17.8 & 48.1 & 6.3 & 27.9 \\
\hline \multicolumn{6}{|l|}{ North Dakota } \\
\hline Large & 74 & 48.7 & 50.1 & 0.0 & 1.4 \\
\hline \multicolumn{6}{|l|}{ Texas } \\
\hline Small & 96 & 50.1 & 0.0 & 49.0 & 1.0 \\
\hline Large & 44 & 31.9 & 0.0 & 61.4 & 6.8 \\
\hline
\end{tabular}

${ }^{a}$ Field location and quadrat size.

Table 2. Frequencies of Beet necrotic yellow vein virus (BNYVV) and Beet soilborne mosaic virus (BSBMV) in samples collected from fields in Minnesota (L1, L2, L3, LR, S1, W1, and W4) and North Dakota (F2 and F3) in 2000

\begin{tabular}{lccccc}
\hline & & \multicolumn{4}{c}{ Virus incidence (\%) } \\
\cline { 3 - 6 } Field $^{\mathbf{a}}$ & No. of samples & None & BNYVV & BSBMV & Both \\
\hline L1 & 53 & 30.2 & 54.7 & 3.8 & 11.3 \\
L2 & 56 & 41.1 & 25.0 & 19.6 & 14.3 \\
L3 & 50 & 22.0 & 36.0 & 0.0 & 42.0 \\
LR & 70 & 48.6 & 20.0 & 24.3 & 7.1 \\
S1 & 107 & 30.8 & 7.5 & 48.6 & 13.1 \\
F2 & 50 & 92.0 & 6.0 & 2.0 & 0.0 \\
F3 & 45 & 80.0 & 17.8 & 2.2 & 0.0 \\
W1 & 50 & 4.0 & 94.0 & 0.0 & 2.0 \\
W4 & 54 & 31.5 & 50.0 & 9.3 & 9.3 \\
\hline
\end{tabular}

${ }^{\mathrm{a}} \mathrm{L} 1, \mathrm{~L} 2$, and L3 are sections of the same large field. needed and the plants were thinned to one per container after emergence. Tachigaren (70\% WP; Gustafson, Mckenney, TX) was added to soil at the rate of $0.05 \mathrm{~g} /$ liter for control of Aphanomyces root rot. Plants were harvested after 4 months and then roots were washed free of soil and prepared for serological tests. Serological tests on the viruses were conducted using double-antibody sandwich (DAS)-ELISA procedures as previously described (9).

Analyses. The incidence and frequency of association of the two viruses was determined using the $\chi^{2}$ statistic in a two-way frequency table. There were no apparent differences in incidence of each virus between the symptomatic and nonsymptomatic sections of fields F2, F3, W1, and W4 and, thus, the two sections in each field were pooled for the analysis. Pooling was done to increase the sample sizes to a level comparable with the other fields (Table 1). Data from these four fields were used only for frequency analysis. Geostatistcal analysis (on the rest of the data) was conducted on categorical data from ELISA results to determine the spatial distribution and covariation of the viruses. Semivariograms (plot of similarity between values as a function of separation distance) were generated to determine the spatial dependence of values of sampling locations. In semivariogram plots, increase in semivariance with the corresponding increase in separation distance indicates spatial dependence (structured pattern), whereas constant values at all separation distances are an indication of randomness $(2,17)$. Hence, in random distribution, values of semivariance run parallel with separation distances. In this study, several semivariogram models were tested to determine their relative fit in describing the spatial variation of each of the viruses, and crosssemivariogram (a semivariogram of two spatially-related variables; in this case, the two viruses) was constructed for samples from each field to determine the spatial covariation of the viruses. Geostatistical terms have been described previously by several authors in describing spatial patterns of plant pathogens or diseases $(1,2,6,12,15,21)$. Therefore, to avoid unnecessary repetition, the terms will not be described here. Frequency analysis was conducted using SAS software (SAS Institute Inc, Cary, NC). Geostatistical analysis was conducted using $\mathrm{GS}^{+}$software (Gamma Design Software, Plainwell, MI).

\section{RESULTS}

In fields sampled in 1999 from Colorado, Minnesota, North Dakota, and Texas, in both large and small quadrats, the viruses were detected in more than $49 \%$ of the samples (Table 1). The incidence of BNYVV was greater than that of BSBMV in samples from Minnesota and North Dakota in both large and small quadrats. However, in samples from Colorado and 
Texas, the incidence of BSBMV was greater than that of BNYVV. In all cases, the viruses were detected in greater frequencies singly than in association. The frequencies of samples in which both viruses were detected in the same sample ranged from $1 \%$ in samples from Texas to $27.9 \%$ in samples from Minnesota and, overall, the viruses were not significantly associated.

Soil samples collected in 2000 from fields in Minnesota and North Dakota had virus frequencies similar to those observed in 1999. With the exception of samples from two fields (F2 and F3), in which the viruses were detected in less than $21 \%$ of the samples, more than $50 \%$ of the samples had at least one of the viruses (Table 2). The relative incidence of the viruses was also generally similar to that in samples collected in 1999 from Minnesota and North Dakota, with higher incidence of BNYVV than BSBMV. The percentage of samples in which both viruses were detected in the same sample ranged from 0 to $42 \%$. The overall association of the viruses was not significant except in samples from L3, in which $42 \%(P<0.05)$ of the samples contained both viruses.

In fields sampled in 1999, the spatial pattern of the viruses showed slight variations among fields but, in large part, appeared to be random. Semivariograms for BNYVV in samples collected from Colorado from small quadrats exhibited sinusoidal behavior, indicating the existence of a spatially periodic component: alternating spatially continuous and discontinuous locations as separation distance increased (Fig. 1A). The spatial pattern of BSBMV exhibited similar behavior but the sinusoidal pattern was less apparent (tending more toward randomness) than that of BNYVV
(Fig. 1B). Samples collected from the small quadrats in Minnesota showed spatial dependency within a range of $29.6 \mathrm{~m}$ (Fig. 1C). Semivariance for BNYVV was best described by the spherical model $\left(r^{2}=\right.$ 0.97 ), and the spatial structure accounted for $82.4 \%$ of the sill. The spatial pattern of BSBMV had less structure than that of BNYVV with an effective range of $13.8 \mathrm{~m}$ (Fig. 1D), and the pattern was best described by the exponential model $\left(r^{2}=0.86\right)$. BNYVV was detected in only one sample from the field in Texas and, hence, the spatial pattern of BNYVV was not determined. The spatial patterns of BSBMV showed no structural pattern. A constant semivariance was observed in all directions in relation to an increase in separation distance (Fig. 2A), which is characteristic of a random distribution pattern $(2,17)$.

Semivariograms for data from large quadrats $(0.4 \mathrm{ha})$ for both viruses in all fields showed random spatial patterns (Fig. $2 \mathrm{~B}$ and $\mathrm{C})$. In addition, both the nugget and the sill values were the same, indicating that proportions of the spatial structure that accounted for the sill was zero (characteristic of lack of spatial structure). However, there was a slight cyclical pattern in the distribution of both viruses, indicating the presence of locally alternating continuous and discontinuous structures. The semivariograms of data from all of the largequadrat fields were similar; therefore, only that of one field representing spatial patterns of both viruses is presented here. In addition, the incidence and distribution patterns of both viruses representing the large quadrats (for which the semivariogram is shown in Figs. 2B and C) are shown in Figure 3.

Semivariograms for samples collected in 2000 from fields in Minnesota were similar

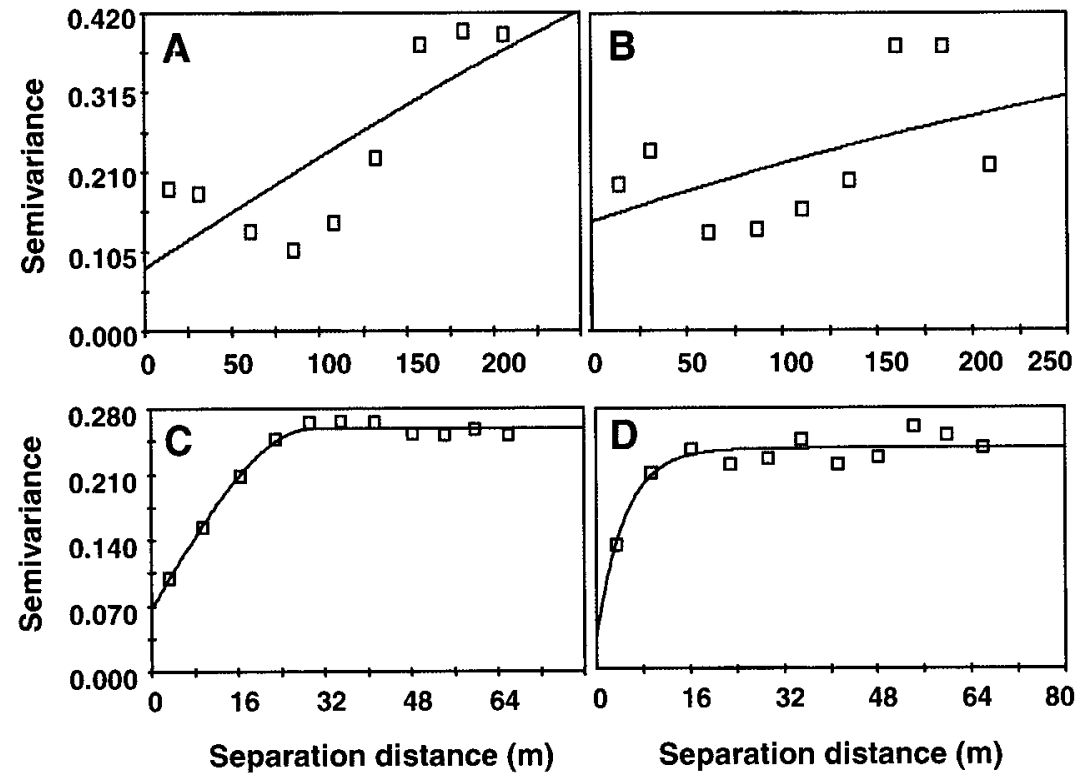

Fig. 1. Semivariograms of spatial patterns of $\mathbf{A}$, Beet necrotic yellow vein virus (BNYVV) and $\mathbf{B}$, Beet soilborne mosaic virus (BSBMV) in soil samples collected from fields in Colorado and of C, BNYVV and D, BSBMV in Minnesota from small quadrats (3.4 by $7.6 \mathrm{~m}$ ) in 1999 . to those of samples collected in 1999. In all fields (except L3) sampled at various-size quadrats, semivariograms for both viruses exhibited characteristics of randomness (lack of change in semivariance with a change in separation distance) in all directions. Semivariograms for samples from L3 showed slight spatial dependence to a range of $8.8 \mathrm{~m}$ for BNYVV and to a range of $3.3 \mathrm{~m}$ for BSBMV (Fig. 4A and B, respectively).

Cross-semivariance analysis for both viruses indicated that, of the seven fields investigated over the 2-year period, sampling locations were jointly spatially dependent for both viruses in only two fields. In samples from the small quadrat in Minnesota (sampled in 1999), sampling locations of both viruses were spatially dependent to a range of $31.4 \mathrm{~m}$ (Fig. 5A) which means that, within this range, the incidence of BNYVV can be estimated from that of BSBMV and vice versa. The spatial pattern was best described by the Gaussian model $\left(r^{2}=0.96\right)$ and the spatial structure accounted for $99 \%$ of the sill. The co-spatial dependence of both viruses was less apparent in samples from L3 (Fig. 5B).

\section{DISCUSSION}

BNYVV and BSBMV are closely related pathogens and are widely distributed

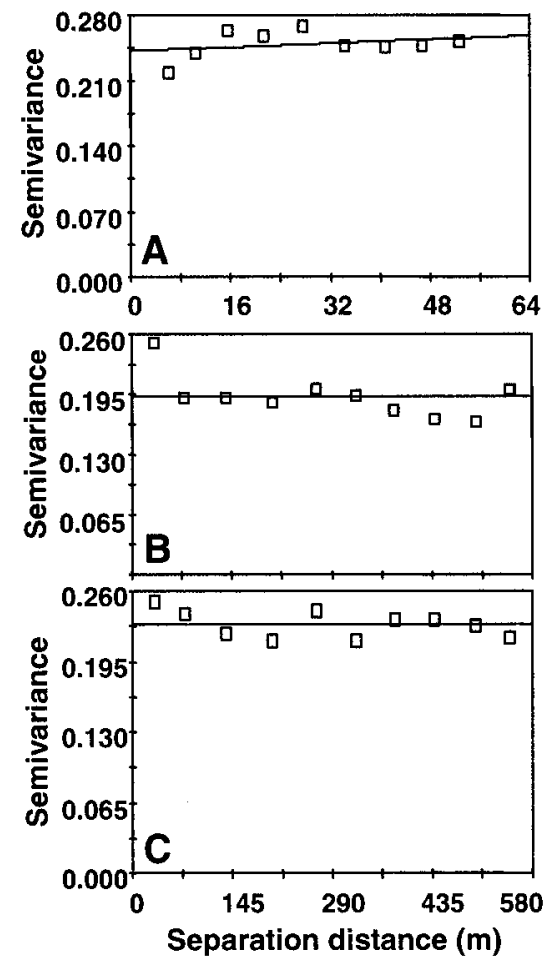

Fig. 2. Semivariograms of spatial patterns of $\mathbf{A}$, Beet necrotic yellow vein virus (BNYVV) in samples collected from small quadrats (3.4 by $7.6 \mathrm{~m}$ ) in Texas, and of A, BNYVV and B, Beet soilborne mosaic virus in samples collected from large quadrats ( $0.4 \mathrm{ha})$ from Minnesota in 1999. 
in sugar beet-growing regions of the United States. Both pathogens are vectored by the zoospores of the soilborne plasmodiophoromycete $P$. betae. There had been reports on incidence of each virus on a regional basis $(9,19)$, but the spatial association and distribution of the viruses in sugar beet fields had never been investigated. In this study, 11 fields were sampled over the 2-year period and data from 7 of them were used for analysis of spatial distribution. The viruses were detected in all fields sampled. The frequency in which both viruses were detected in the same from 0 to $42 \%$. The association of these viruses in soil collected from the rhizospheres of sugar beet suggests that interaction (synergetic or antagonistic) between the viruses during infection or disease development is spatially possible under field conditions, as has been shown experimentally $(14,16,27)$. It would be interesting to determine whether a single zoospore could vector both viruses during infection.

In general, both viruses exhibited similar spatial patterns. The spatial pattern of BNYVV appeared to be slightly more structured than that of BSBMV. There was a greater incidence of BNYVV than BSBMV in most of the fields, and the level of incidence may have contributed to slight differences observed in the structure of their spatial distributions. However, in large part, the spatial distribution of both viruses exhibited a random pattern at the specified sampling distances. The existence of spatial dependency in a field enables one to interpolate incidence of the viruses in unsampled locations. However, sampling distances affect the outcome of spatial pattern investigation (26). Spatial pattern of a subject under study may apsample varied among fields and ranged

pear random if sampled at distances beyond the range at which it is spatially dependant. Furthermore, selection of distances at which spatial continuity can be detected may be difficult to achieve. In addition, small sampling distances require greater resources than large distances, and one has to have a balanced approach between available resources and the objective of the study. In this study, fields were sampled at various sampling distances (quadrat sizes) and a random pattern was observed in most of them. None of the fields sampled at large grids $(\geq 0.4 \mathrm{ha})$ showed spatial dependency for either virus. These distances may have been too large to detect the existence of spatial continuity. However, only two of the five fields sampled at small grids ( 2.9 by $2.9 \mathrm{~m}$ and 3.4 by $7.6 \mathrm{~m}$ ) exhibited any degree of spatial continuity. This may indicate that, for all practical purposes, the viruses are randomly distributed. However, it still is possible that spatial patterns of the viruses in these fields may not have turned out to be random if they were further sampled at smaller distances than the smallest grids used in this study. Gerik and Duffus (7) observed clustering of BNYVV in some directions in fields in California. However, they did not indicate their sampling distances. In the present study, the spatial patterns were similar in all directions at all sampling distances.

The fact that both viruses exhibited similar patterns of spatial distribution is interesting but not surprising because both are vectored by the same organism and, in a real sense, we investigated the spatial patterns of the viruliferous vector. It would be more interesting to estimate the frequency and distribution pattern of one virus from that of the other in fields in which both are prevalent. This may be possible in fields

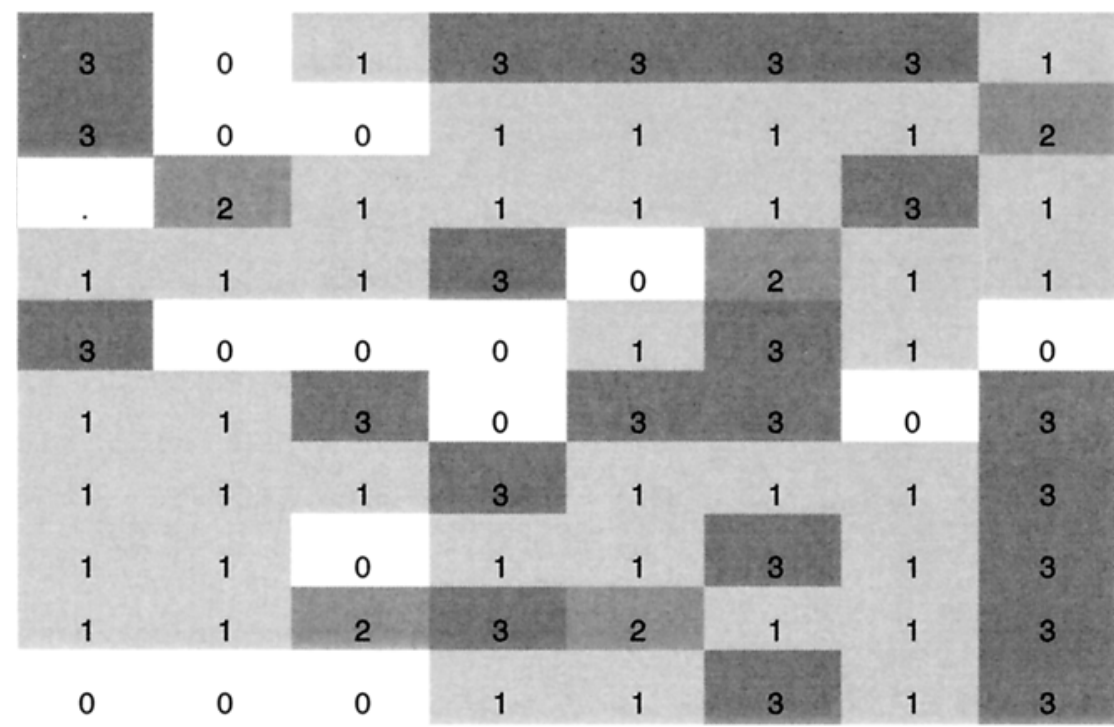

Fig. 3. A plot of incidence, spatial distribution, and association of Beet necrotic yellow vein virus (BNYVV) and Beet soilborne mosaic virus (BSBMV) in samples collected from the large quadrats $(0.4 \mathrm{ha})$ from the field in Minnesota in 1999. A quadrat marked with $0=$ no virus present, $1=$ BNYVV present, $2=$ BSBMV present, $3=$ both viruses present, and a dot $=$ missing. where distributions of both viruses are spatially dependent and the two viruses are strongly associated. Estimations based on covariations of two variables have been successfully achieved in the past using cross-semivariograms in conjunction with cokriging $(22,30,31)$. In the present study, the association between the two viruses overall was weak and their spatial patterns in most cases were random. Meaningful cross-semivirograms could be constructed in samples from only two of the seven

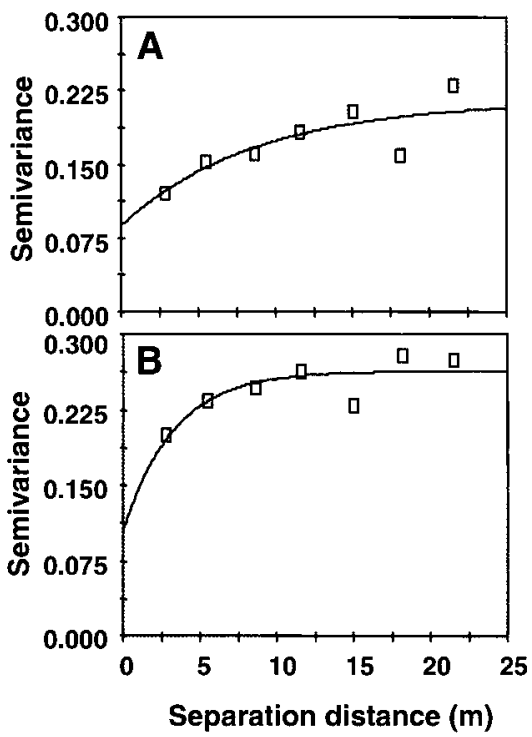

Fig. 4. Semivariograms of spatial patterns of $\mathbf{A}$, Beet necrotic yellow vein virus and $\mathbf{B}$, Beet soilborne mosaic virus in samples collected from a field (L3) sampled in a 2.9-by-2.9-m quadrat from the field in Minnesota in 2000.

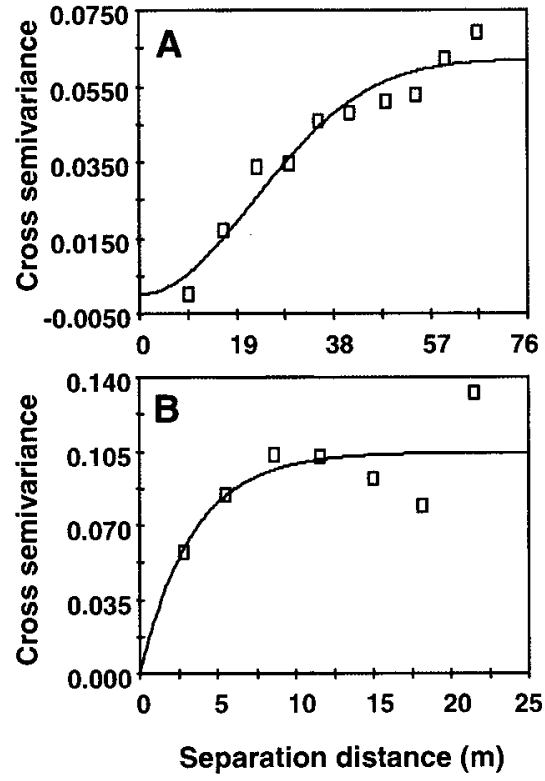

Fig. 5. Cross semivariogram of spatial patterns of Beet necrotic yellow vein virus and Beet soilborne mosaic virus in samples collected from the fields in Minnesota in small quadrats in $\mathbf{A}, 1999$ and $\mathbf{B}, 2000$. 
fields. Lack of ability to estimate variability of one virus from that of the other may largely be attributed to absence of spatial continuity in sampling locations of both viruses. The random distribution pattern detected in this study may be associated, in large part, with the movement of the vector by tillage implements $(20,23)$. Horizontal dispersal of the vector has been shown to be negligible either by zoospore movements or displacement by irrigation water $(8,24,25)$.

The study showed that both viruses exhibited more or less similar spatial patterns. Thus, a sampling strategy employed for one of the viruses may be utilized for the other as well. In general, the study suggested that a random sampling may be the best method, but this could depend on cultural history and time since the introduction of the pathogens into the field.

\section{LITERATURE CITED}

1. Chellemi, D. O., Rohrbach, K. G., Yost, R, S., and Sonoda, R. M. 1988. Analysis of spatial pattern of plant pathogens and diseased plants using geostatistics. Phytopathology 78:221-226.

2. Davis, J. C. 1986. Statistics and Data Analysis in Geology. 2nd ed. John Wiley, New York.

3. Duffus, J. E., and Liu, H. Y. 1987. First report of rhizomania of sugar beet from Texas. Plant Dis. 71:557.

4. Duffus, J. E., Whitney, E. D., Larson, R. C., Liu, H. Y., and Lewellen, R. T. 1984. First report of in Western Hemisphere of rhizomania of sugar beet caused by beet necrotic yellow vein virus. Plant Dis. 68:251.

5. Fujisawa, I., and Sugimoto, T. 1976. Transmission of beet necrotic yellow vein virus by Polymyxa betae. Ann. Phytopathol. Soc. Jpn. 43:583-586.

6. Gavassoni, W. L., Tylka, G. L., and Munkvold, G. P. 2001. Relationships between tillage and spatial patterns of Heterodera glycines. Phytopathology 91:534-545.

7. Gerik, J. S., and Duffus, J. E. 1989. Spatial occurrence of Polymyxa betae and beet necrotic yellow vein virus in California sugar beet fields. J. Sugar Beet Res. 26:A8.

8. Harveson, R. M., and Rush, C. M. 1993. A simple method for field and greenhouse inoculation of Polymyxa betae and beet necrotic yellow vein virus. Phytopathology 83:1216-1219.

9. Heidel, G. B., and Rush, C. M. 1994. Distribution of beet necrotic yellow vein virus, beet distortion mosaic virus, and unnamed sugar beet virus in Texas and New Mexico. Plant Dis. 78:603-606.

10. Heidel, G. B., Rush, C. M., Kendall, T. L., Lommel, S. A., and French, R. C. 1997. Characteristics of beet soilborne mosaic virus, a furo-like virus infecting sugar beet. Plant Dis. 81:1070-1076.

11. Koenig, R., and Lennefors, B. L. 1999. Molecular studies on rod-shaped Ploymyxatransmitted sugar beet viruses in Europe and Kazachstan. Pages 37-40 in: Proc. Fourth Symp. Int. Working Group on Plant Viruses with Fungal Vectors. J. L. Sherwood and C. M. Rush, eds. The American Society of Sugar Beet Technologists, Denver.

12. Larkin, R. P., Gumpertz, M. L., and Restaino, J. B. 1995. Geostatistical analysis of Phytophthora epidemic development in commercial paper fields. Phytopathology 85:191-203.

13. Liu, H.-Y., and Duffus J. E. 1988. The occurrence of a complex of viruses associated with Rhizomania of sugarbeet. (Abstr.) Phytopathology 78:1583.

14. Mahmood, T., and Rush, C. M. 1999. Evidence of cross-protection between beet soilborne mosaic virus and beet necrotic yellow vein virus in sugar beet. Plant Dis. 83:521526.

15. Munkvold, G. P., Duthie, J. A., and Marois, J. J. 1993. Spatial patterns of grapevines with Eutypa dieback in vineyards with or without perithecia. Phytopathology 83:1440-1448.

16. Piccinni, G., and Rush, C. M. 2000. Determination of optimum irrigation regime and water use efficiency of sugar beet grown in pathogen-infested soil. Plant Dis. 84:10671072.

17. Rossi, R. E., Mulla, D. J., Journel, A. G., and Franz, E. H. 1992. Geostatistical tools for modeling and interpreting ecological spatial dependence. Ecol. Monogr. 62:277-314.

18. Rush, C. M., French, R. C., and Heidel G. B. 1994. Differentiation of two closely related furoviruses using the polymerase chain reaction. Phytopathology 84:1366-1369.

19. Rush, C. M., and Heidel, G. B. 1995. Furovirus diseases of sugar beet in the United States. Plant Dis. 79:868-875.

20. Schlosser, E. 1988. Epidemiology and man- agement of Polymyxa betae and beet necrotic yellow vein virus. Dev. Appl. Biol. 2:281292.

21. Stein, A., Kocks, C. G., Zadocks, J. C., Frinking, H. D., Ruissen, M. A., and Meyers, D. E. 1994. A geostatistical analysis of spatiotemporal development of downy mildew epidemics in cabbage. Phytopathology 84:12271234

22. Stein, A., van Dooremolen, Bouma, J., and Bregt, A. K. 1988. Cokriging point data on moisture deficit. Soil Sci. Soc. Am. J. 52:1418-1423.

23. Truscott, J. E., and Gilligan, C. A. 2001. The effect of cultivation on size, shape, and persistence of disease patches in fields. Proc. Natl. Acad. Sci. USA 98:7128-7133.

24. Tuitert, G., and Hofmeester, Y. 1993. Horizontal spread of beet necrotic yellow vein virus in soil. Neth. J. Plant Pathol. 99:85-96.

25. Tuitert, G., and Hofmeester, Y. 1994. Epidemiology of beet necrotic yellow vein virus in sugar beet at different inoculum levels in the presence or absence of irrigation: Disease incidence, yield and quality. Eur. J. Plant Pathol. 100:19-53.

26. Warrick, A. W., Meyers, D. E., and Nelson, D. R. 1986. Geostatistical methods applied to soil science. Pages 53-82 in: Methods of Soil Analysis: Part 1-Physical and Mineralogical Methods. 2nd edition. A. Klute, ed. The American Society of Agronomy and Soil Science Society of America, Madison, WI.

27. Wisler, G. C., Lewellen, R. T., Liu, H.-Y., and Wintermantel, W. M. 2001. Interaction between BNYVV and BSBMV in rhizomania resistant and susceptible varieties and effects on beet development. (Abstr.) J. Sugar Beet Res. 38:106.

28. Wisler, G. C., Liu, H.-Y., and Duffus, J. E. 1994. Beet necrotic yellow vein virus and its relationship to eight sugar beet furo-like virus forms in the United States. Plant Dis. 78:9951001.

29. Wisler, G. C. Widner, J. N., Duffus, J. E., Liu, H. Y., and Sears, J. L. 1997. A new report of rhizomania and other furoviruses infecting sugar beet in Minnesota. Plant Dis. 81:229.

30. Yates, S. R., and Warrick, A. W. 1987. Estimating soil water content using cokriging. Soil Sci. Soc. Am. J. 51:23-30.

31. Zhang, R., Shouse, P., and Yates, S. 1997. Use of pseudo-cross variograms and cokriging to improve estimates of soil solute concentrations. Soil Sci. Soc. Am. J. 61:1342-1347. 